\title{
Stakeholder Analysis: Using the Jigsaw Method for Ethical Dilemmas in Business
}

\author{
Leigh N. Wood (Corresponding author) \\ Faculty of Business and Economics, Macquarie University \\ Sydney, NSW 2109, Australia \\ Tel: 61-2-9850-4756Ｅ-mail: leigh.wood@mq.edu.au \\ Peter Dixon \\ Faculty of Business, University of Tasmania \\ Launceston, Tasmania 7250, Australia \\ Tel: 61-3-6324-3329Ｅ-mail: Peter.Dixon@utas.edu.au
}

Received: February 1, $2011 \quad$ Accepted: February 23, $2011 \quad$ doi:10.5539/ass.v7n4p77

Support for this project was provided by the Australian Learning and Teaching Council, an initiative of the Australian Government Department of Education, Employment and Workplace Relations. The views expressed in this paper do not necessarily reflect the views of the Australian Learning and Teaching Council Ltd.

\begin{abstract}
Stakeholder analysis is an essential part of business education as students develop awareness of the different perspectives that influence business and the difficult decisions made by business, government and communities. An important aspect of learning is to think critically about who is presenting the viewpoint and the conclusions they have drawn. We have found that the Jigsaw Method is a powerful way to learn the importance of different viewpoints in the teaching of ethical practice and sustainability.
\end{abstract}

Keywords: Business education, Ethical practice, Jigsaw method, Stakeholder analysis, Green learning, Sustainability

\section{Introduction}

Analysis of different viewpoints is an important step to appreciating the dilemmas that face businesses and governments as they make decisions. Should forests be logged? Should hotel employees wear headscarves? Should you use Facebook in work time? Should we drill for oil in the Gulf of Mexico? Should vacant land be flooded for dam construction? Should development of flood-prone land be permitted? It is critical to ensure that students are able to analyze the types of circumstances they will encounter in the workplace. In this paper we focus on the ethical and sustainability aspects of problem situations, which allows us to illustrate the range of stakeholder viewpoints that graduates will encounter and that can be extended to other aspects. Our context is the embedding of graduate skills in business education. Our work has centred on seven universities in Australia but is generalisable to a variety of contexts where students are developing critical thinking skills and analyzing different stakeholder views.

This paper describes the jigsaw method as a useful technique for supporting the development of skills in stakeholder analysis.

\subsection{Graduate skills}

There is a gap between the rhetoric and reality about embedding graduate skills in the curriculum. The first key practice to enhance the delivery of graduate skills is to embed graduate skills in disciplinary curricula. Research has consistently identified that high-level graduate skills are most effectively developed in the context of disciplinary knowledge, embedded within disciplinary curricula rather than addressed by separate strategies that 
are divorced from the discipline context (Barrie, 2004; Thompson et al., 2008; Bath et al., 2004). Remedial courses and separate non-discipline specific workshops that are removed from the disciplinary learning environments "run the risk of promoting a shallow, technical approach to teaching and learning" (Star \& Hammer, 2007, p. 241). However, these same authors also question whether or not embedding skills such as critical thinking in context-specific learning also leads to students adopting a critical perspective in relation to other practices and other forms of knowledge outside of that discipline.

As researchers and academics have come to address the teaching and learning of graduate skills, there has been and still is a clear polarization, between the embedding and integration of graduate skills in the curriculum (Barrie, 2004; Thompson et al., 2008) and the creation of separate, non-discipline specific courses or workshops (Cranmer, 2006). Broadly, this reflects a "pedagogical trading zone between the graduate skills agenda and education's higher historic purpose" (Star \& Hammer, 2007, p. 244). That is, it reflects academics' fundamental attitudes to core teaching and learning pedagogy. For the former approach (embedding), it reflects the view that teaching must change to meet the learning needs of an increasingly diverse student cohort, and student-centred pedagogy is one particular manifestation of this position (Biggs, 2003). For the latter (separate treatment), there is a distinct focus on what the student lacks, and it is a position that does not incorporate students' learning difficulties and deficiencies in the design of teaching practice; for instance, it does not allow for the large number of local and international students who start their tertiary studies without the necessary skills to engage in their discipline community.

This debate can also be found in the literature pertaining to specific graduate skills, such as critical thinking and ethical practice, and whether such skills should be embedded in course curricula or taught separately. This implementation gap can be linked partly to the divergent and conflicting understandings and conceptualizations of graduate skills (and indeed the skills themselves) found amongst academic staff. Researchers point out that the notion of graduate skills has a very weak theoretical and conceptual base (Barrie, 2004; Clanchy \& Ballard, 1995; Sin \& Reid, 2006). For example, Drummond, Nixon and Wilkshire's (1998) research from the UK highlights the inherent difficulties in implementing good practice models for skills development. The authors identified institutional, departmental and individual barriers, and that the " 'dissemination' of information regarding what constitutes good practice will not, in itself, be sufficient to ensure meaningful development." (p. 19) There is also evidence that embedding and integrating skills development has been "difficult to operationalise effectively" (p. 21).

\subsection{Stakeholder analysis}

Finding and analyzing the positions of the important stakeholders in a particular context is an excellent way for students - and others - to step outside their own positions and critically view the position of a variety of interested parties. With so many ethical dilemmas in business affecting a variety of stakeholders, the ability to see different perspectives is critical.

In the next section we describe the jigsaw method for stakeholder analysis.

\section{Background: the jigsaw method}

The jigsaw method is a cooperative learning technique which uses teamwork to achieve learning (see Aronson et al., 1978; Slavin 1983, 1990). Originally developed by Aronson in 1971 to address racial stereotyping and prejudice in schools, it was later extended for use in higher education by Goodsell et al. (1992). While the technique has been adopted in business and management education (Mesch, 1991), this is not well documented.

\subsection{Description of the technique}

In the jigsaw method the lecturer divides the class into groups of five or six students. The lesson is also divided into five or six parts, with one part of the lesson given to each student in a jigsaw group. Each member of a team becomes an "expert" in one area and then is responsible for teaching the rest of the team. Prior to teaching in jigsaw groups, students meet in "expert" groups with their counterpart from other groups to help each other prepare to teach their part to their respective jigsaw groups. In the jigsaw group, each student teaches a necessary and unique piece of information to help the group master the assigned work. When the unit is completed, the students are tested and they each receive a grade based upon their own test performance. This contrasts with other cooperative learning techniques in which students receive a grade based upon their group performance.

Jigsaw II (Slavin, 1983, 1990) is an adaptation of the jigsaw approach in which individual scores are combined at the end of the task to yield a team score. As per Jigsaw 1, students are assigned to small teams and each team member is given a topic on which to become an expert. The students discuss their topics in expert groups then return to teach their teammates what they have learned. The exact method of the cooperative incentive varies, 
with the most popular variations being:

- group scores based on the individual scores of members (for example quiz scores used to form both individual and team scores); and

- group scores based on a group project or another product.

The jigsaw method fosters positive interdependence through collaboration and peer teaching in order to get the "big picture". Thus the technique develops both academic and social competencies. Mesch (1991) identifies the following benefits and pitfalls of the technique:

- Benefits - high levels of student enjoyment and satisfaction; a better understanding of the topic because of having to teach it to someone else; students taking responsibility for the teaching-learning process; high attendance rates.

- $\quad$ Pitfalls - some students have difficulty learning material on their own; diversity in ability levels can lead to frustration; a student's absence when it is their turn to teach disrupts the process for others; although the technique ensures individual accountability some students may still want others to do all the work.

\subsection{Use of jigsaw in business and management studies}

While there is a large body of research examining the use of the jigsaw technique in primary and high school settings, fewer studies have investigated its application to teaching in university classrooms. Available studies are based mainly in the disciplines of engineering, social sciences, language/literacy (including EAL) and education. There are fewer reported studies which focus on the use of the jigsaw method in business and management education (Holtham, Melville, \& MacMohan, 2006; Lebaron \& Miller, 2005; Mesch, 1991), although there is a substantial body of literature on the use of cooperative learning techniques in business education (Bacon, 2005; Siciliano, 2001). The use of stakeholder analysis and approaches in relation to business/management education, particularly in teaching ethics (Brinkmann \& Sims, 2001; Goodpaster, 1991) and sustainability (Collins \& Kearins, 2007) has been more widely reported.

\section{Case study}

Here we describe how we have adapted the jigsaw method for stakeholder analysis in business education and have spread its use out to business schools around Australia. These models are readily adaptable to other disciplines. For our case studies we identified authentic scenarios where community debate exists and where there is a genuine dilemma attached to a final decision. By requiring each student to become a stakeholder for a particular group, they are forced to take on an opinion that they may not agree with and argue from that viewpoint.

\subsection{Creating an ethical or green dilemma}

Properly developing the situation of the dilemma for teaching practice is crucial. Students need to feel that they are working on a real task in order for there to be significant engagement, and of course any task will differ depending on the current or local context. For example, a dilemma about the use of recycled water is important in Australia where there is still significant debate, but not in Singapore where using recycled water is the norm. What makes it particularly interesting in class is when there are students from a variety of countries with different norms. Examples of ethical dilemmas are available on the graduate skills website (www.graduateskills.edu.au).

\subsection{Example: Gunns'proposed pulp mill in Tasmania, Australia (Appendix A)}

Tasmania is a State of Australia, and is an island to the south of the mainland of Australia. It has a relatively clean environment and is making a name for itself for high-quality cool-climate foods, wines and tourism. However, there is also a proud tradition of logging and the State has significant forestry reserves. Tasmania has the highest unemployment rate in Australia and generally does not have the opportunities afforded other States. However, there is good hydroelectricity available, good infrastructure and a well-educated workforce.

Enter the company Gunns Limited (http://www.gunnspulpmill.com.au/), who has proposed a pulp mill in the north of Tasmania which will use Tasmanian resources. Should the mill go ahead? What sustainability issues does the Project raise? What is the effect of those issues on whether the Project should proceed unconditionally, or with conditions attached? These considerations were raised rhetorically in class during the introduction to this activity. It is important to note that the students were not presented with a specific definition of sustainability, which we have described elsewhere (Petocz \& Dixon, in this Issue) as three dimensional (environmental, organizational, and concern for present and future generations); rather we expected such an understanding to 
emerge from the discussion.

For our stakeholder analysis we identified five key stakeholders:

- Government

- Workers

- Gunns Limited

- Community

- Conservationists.

There are other stakeholder groups that could have been identified, but these were sufficient for our workshop. To trial the jigsaw method and the learning resources, we used seven groups of five students; each of the five students became a stakeholder for one of the stakeholder groups above. The schema for the analysis is presented in Figure 1.

The students were allocated randomly to join a particular stakeholder group, although the original group of five was not allocated randomly but were chosen by the facilitators. Each original group of five was given additionally a statement of common facts relating to the Project.

\subsubsection{Becoming experts}

The seven students in each stakeholder group met for 20 minutes to "become" the stakeholder and develop the identity and knowledge of that stakeholder. They were given information pertaining to the view of that stakeholder. Because this was a short exercise we did not expect students to seek information outside that which they had been given.

\subsubsection{Taking a role}

The students then moved back to their original group of five, now containing the five different stakeholders. Discussion ensued to find a team position as to whether the Project should proceed, and if so upon what terms. The groups were given a set of suggested questions that required consideration of the sustainability of the Project. The negotiation of roles and development of a team position creates a challenge because each student represents a different stakeholder group, so each team member has (potentially) conflicting agendas.

\subsubsection{Finale}

Each group presented their final position to the entire group who then voted for a "people's choice" award.

\subsubsection{Reflection}

During the course of student presentations it became evident that the groups had discussed what was understood by "sustainability", albeit in the context of the case study. To capitalize on these understandings we then conducted a formal teaching session on notions of sustainability immediately following this activity.

\subsection{Student response}

Student response was extremely positive, and observations showed that students were highly engaged in the activity. Here are some comments from students at the end of the workshop:

We did the group-work thing where we did a presentation on a paper mill in Tasmania. That was one thing that made me think about the environment and the effects that humans are having on it more so than probably what I was thinking about it before.

It was having that interaction as like a board and then moving away and having community interaction as well. I thought it was good to get different views on things. That was probably the most significant [activity]. This has changed my understanding of sustainability ... straight away my thoughts were, look at it from this person's view then this one, then this one et cetera. It's almost like a natural way of thinking now.

The student responses suggest that the jigsaw activity produced in some students an awareness of the issues presented in the scenario as well as an appreciation of the views of others.

\section{Discussion}

The Gunns case study has now been implemented in business programs around Australia due to dissemination through the Australian Business Deans' Council Learning and Teaching Network. The materials and instructions for use are available on the graduate skills website.

The use of the jigsaw method made it easy for facilitators to design case studies for stakeholder analysis and 
encouraged role playing, which also helped to develop critical thinking skills. Participants needed to analyze the information of each stakeholder from the viewpoint of the stakeholder. It was clear that stakeholders use information differently to further their point of view and students did exploit this opportunity themselves.

The method is readily transferable to other situations involving defined stakeholder positions. The use of the jigsaw method in this context mirrored its extensive use at school level. Australian university cohorts have students from many backgrounds, including international students, mature-aged students and students fresh from secondary school. Many students speak languages other than English and may come from varied cultural backgrounds. The technique works to mix groups and gives all participants a role and an expert authority. Our experience confirms the use of the jigsaw method in culturally and linguistically diverse groups to enhance learning and intercultural competence.

The method also worked well for stakeholder analysis. It held the students' attention and honed various skills through the role-playing activity. The skills learnt were used in subsequent unstructured case studies, showing that the jigsaw method gave students a structure they could transfer to other situations. This is the real power of the method. The benefits also included critical thinking skills, as students were able to analyze the view of the stakeholders in how the material was presented and how the same data can be used to argue different viewpoints. More importantly, the method provides a substantial contribution to the design of activities and assessment tasks that embed "professional 'qualities' and vocational 'competencies'" (Patterson \& Bell, 2001, p. 454) in programs, course and units. In particular the method provides an opportunity for students to undertake experiential, negotiated, collaborative and reflective learning activities (Paterson \& Bell, 2001) in the context of real-world situations. Our Project has demonstrated elsewhere that student performance in these regards can be measured using the criteria that we developed (see Wood, Thomas, \& Rigby in this Issue).

The structure of the jigsaw method makes it an ideal exercise in stakeholder analysis in sustainability and ethical dilemmas, and is readily usable in introductory, intermediate or advanced units of study. It is valuable in the Australian context where tutorial sizes are approximately 25 to 35 and we recommend its use for business contexts with similar class sizes.

\section{References}

Aronson, E., Blaney, N., Stephen, C., Sikes, J., \& Snapp, M. (1978). The jigsaw classroom. Beverly Hills, CA: Sage Publications.

Bacon, D. R. (2005). The effect of group projects on content-related learning. Journal of Management Education, 29, 248-267.

Barrie, S. C. (2004). A research-based approach to generic graduate attributes policy. Higher Education Research \& Development, 23, 261-75.

Bath, D., Smith, C., Stein, S., \& Swann, R. (2004). Beyond mapping and embedding graduate attributes: bringing together quality assurance and action learning to create a validated and living curriculum. Higher Education Research \& Development, 23, 313-28.

Biggs, J. (2003). Teaching for quality learning at university. Buckingham: Society for Research into Higher Education and Oxford University Press.

Brinkmann, J., \& Sims, R. R. (2001). Stakeholder-sensitive business ethics teaching. Teaching Business Ethics, 5, 171-193.

Clanchy, J., \& Ballard, B. (1995). Generic skills in the context of higher education. Higher Education Research \& Development, 14, 155-66.

Collins, E., \& Kearins, K. (2007). Exposing students to the potential and risks of stakeholder engagement when teaching sustainability: a classroom exercise. Journal of Management Education, 31(4), 521-540.

Cranmer, S. (2006). Enhancing graduate employability: best intentions and mixed outcomes. Studies in Higher Education, 31, 169-84.

Drummond, I., Nixon, I., \& Wiltshire, J. (1998). Personal transferable skills in higher education: the problems of implementing good practice. Quality Assurance in Education, 6, 19-27.

Goodpaster, K. E. (1991). Business ethics and stakeholder analysis. Business Ethics Quarterly, 1(1), 53-73.

Goodsell, A., Maher, M., \& Tinto, V., with Smith, B., \& MacGregor, J. (1992). Collaborative learning: a sourcebook for higher education. University Park, PA: National Center on Postsecondary Teaching, Learning, and Assessment. 
Holtham, C. W., Melville, R. R., \& MacMohan, S. S. (2006). Designing student groupwork in management education: widening the palette of options. Journal of Management Education, 30, 809-817.

Lebaron, J., \& Miller, D. (2005). The potential of jigsaw role playing to promote the social construction of knowledge in an online graduate education course. Teachers College Record, 107(8), 1652-1674.

Mesch, D. J. (1991). The jigsaw technique: A way to establish individual accountability in group work. Journal of Management Education, 15, 355-358.

Patterson, A., \& Bell, J.W. (2001). Teaching and learning generic skills in universities: the case of "sociology" in a teacher education n programme. Teaching in Higher Education, 6(4), 451-471.

Siciliano, J. I. (2001). How to incorporate cooperative learning principles in the classroom: it's more than just putting students in teams. Journal of Management Education, 25, 8-20.

Sin, S., \& Reid, A. (2006). Developing generic skills in accounting: resourcing and reflecting on trans-disciplinary research and insights. [Online] Available: http://www.aare.edu.au/05pap/sin05143.pdf (January 14, 2011).

Slavin, R. (1983). Cooperative learning. New York: Longman.

Slavin, R. E. (1990). Co-operative learning theory research and practice. London: Allyn \& Bacon.

Star, C., \& Hammer, S. (2007). Teaching generic skills: eroding the higher purpose of universities, or an opportunity for renewal?. Oxford Review of Education, 34, 237-51.

Thompson, D., Treleaven, L., Kamvounias, P., Beem, B., \& Hill, E. (2008). Integrating graduate attributes with assessment criteria in business education: using an online assessment system. [Online] Available: http://jutlp.uow.edu.au/2008_v05_i01/3_Thompson011.html (March 3, 2009).

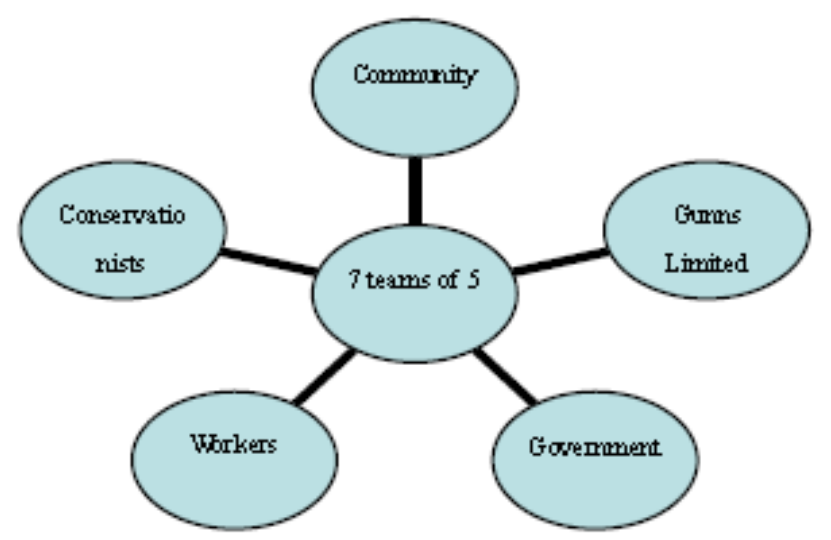

Figure 1. Stakeholder groups and teams

\section{Appendix A: Gunns case study}

\begin{tabular}{|l|l|}
\hline \\
\hline Description & Stakeholder Analysis \\
\hline Task Type & In-class or tutorial activity \\
\hline Level & 50 minutes \\
\hline Class Size & Advanced \\
\hline Learning & Student should 35 students \\
\hline
\end{tabular}




\begin{tabular}{|c|c|}
\hline Outcomes & $\begin{array}{l}\text { Demonstrate an understanding of sustainability in three dimensions: environmental } \\
\text { (green); organisational (long term); responsibility for present and future generations } \\
\text { Develop an argument and counterargument in two contexts }\end{array}$ \\
\hline Method & $\begin{array}{l}\text { Choose a case example of an organisational activity that raises sustainability issues ('the } \\
\text { Project') } \\
\text { Prepare a general factual introduction and up to five statements of the viewpoints of } \\
\text { stakeholders. }\end{array}$ \\
\hline $\begin{array}{l}\text { Concluding } \\
\text { Activity }\end{array}$ & $\begin{array}{l}\text { Link this back to learning about sustainability from the student activity. Issues to address might } \\
\text { be: } \\
\text { What do we mean by sustainability? }\end{array}$ \\
\hline Tips & Keeping time is key to the success of this activity \\
\hline $\begin{array}{l}\text { Student } \\
\text { Instructions }\end{array}$ & 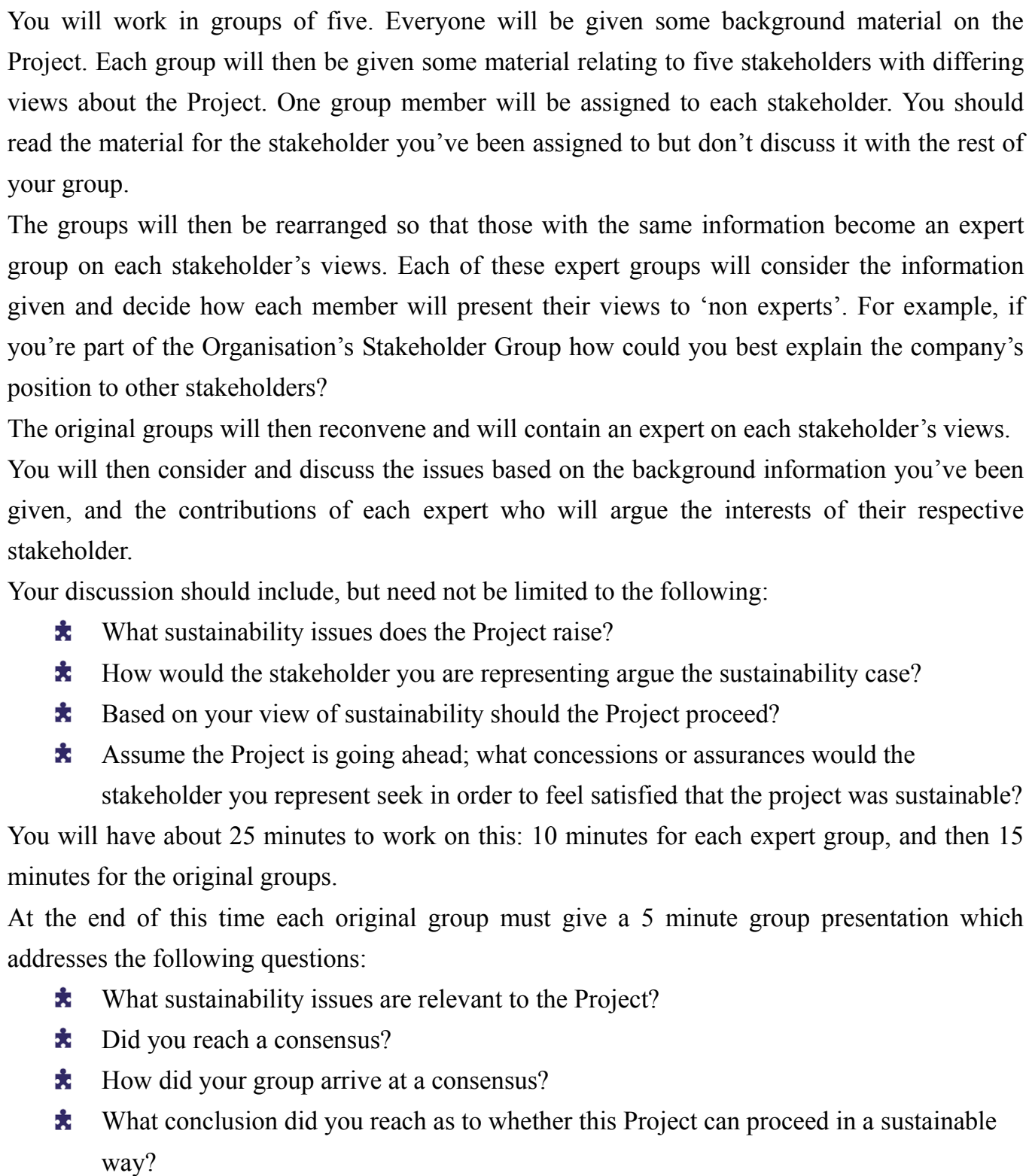 \\
\hline
\end{tabular}

